\title{
Spatial variation in particle number size distributions in a large metropolitan area
}

\author{
J. F. Mejía ${ }^{1}$, L. Morawska ${ }^{1}$, and K. Mengersen ${ }^{2}$ \\ ${ }^{1}$ International Laboratory of Air Quality and Health, Queensland University of Technology, GPO Box 2434, Brisbane, Qld \\ 4001, Australia \\ ${ }^{2}$ School of Mathematical Sciences, Queensland University of Technology, GPO Box 2434, Brisbane, QLD, 4001, Australia
}

Received: 30 August 2007 - Published in Atmos. Chem. Phys. Discuss.: 26 November 2007

Revised: 25 January 2008 - Accepted: 28 January 2008 - Published: 28 February 2008

\begin{abstract}
Air quality studies have indicated that particle number size distribution (NSD) is unevenly spread in urban air. To date, these studies have focussed on differences in concentration levels between sampling locations rather than differences in the underlying geometries of the distributions. As a result, the existing information on the spatial variation of the NSD in urban areas remains incomplete. To investigate this variation in a large metropolitan area in the southern hemisphere, NSD data collected at nine different locations during different campaigns of varying duration were compared using statistical methods. The spectra were analysed in terms of their modal structures (the graphical representation of the number size distribution function), cumulative distribution and number median diameter (NMD). The study found that with the exception of one site all distributions were bimodal or suggestive of bimodality. In general, peak concentrations were below $30 \mathrm{~nm}$ and NMDs below $50 \mathrm{~nm}$, except at a site dominated by diesel trucks, where it shifted to around 50 and $60 \mathrm{~nm}$ respectively. Ultrafine particles (UFPs $(<100 \mathrm{~nm}))$ contributed to $82-90 \%$ of the particle number, nanoparticles $(<50 \mathrm{~nm})$ to around $60-70 \%$, except at the diesel traffic site, where their contribution dropped to $50 \%$. Statistical analyses found that the modal structures heterogeneously distributed throughout Brisbane whereas it was not always the case for the NMD. The discussion led to the following site classification: (1) urban sites dominated by petrol traffic, (2) urban sites affected by the proximity to the road and (3) an isolated site dominated by diesel traffic. Comparisons of weekday and weekend data indicated that, the distributions were not statistically different. The only exception occurred at one site, where there is a significant drop in the number of diesel buses on the weekend. The dif-
\end{abstract}

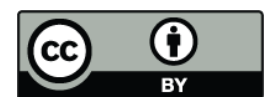

Correspondence to: L. Morawska (1.morawska@qut.edu.au) ferences in sampling period between sites did not affect the results. The statistics instead suggested variations in traffic composition. However, the relative contribution of petrol vehicle emissions at each site could not be assessed due to the limited traffic information available.

\section{Introduction}

Evidence from medical studies indicates that air pollution is a major contributor to cardiovascular and respiratory health problems (e.g. Hong et al., 2002). Until recently, these studies focussed on the particle mass, which is dominated by the coarse $(2.5-10.0 \mu \mathrm{m})$ and fine $(<2.5 \mu \mathrm{m})$ size fractions. Whilst the toxicological importance of these particles cannot be dismissed, it has been suggested that the observed effects could be better explained by the number of the ultrafine fraction $(<100 \mathrm{~nm})$ rather than the mass of the larger particles (Seaton et al., 1995). In urban air, ultrafine particles (UFPs) dominate the particle number size distribution whereas their contribution to the particle mass is negligible (Morawska et al., 1998a, b; Jaenicke, 1993). Therefore, particle number has become the most widely employed parameter for measuring UFP concentration.

Although they are yet to be incorporated into long-term air quality monitoring systems, since the 1990s submicrometre $(<1.0 \mu \mathrm{m})$ and UFP number concentrations have been measured in several cities around the world. Typical urban concentrations range in the order of $10^{3}-10^{5} \mathrm{~cm}^{-3}$ (e.g. Buzorius et al., 1999) with the UFPs accounting for $>80 \%$ of the total particle number (Morawska et al., 1998a, b; Shi et al., 2001). There is wide agreement that vehicles are the principal source of UFPs in urban areas. This has been shown by the strong associations of particle number with vehicle exhaust gases (Morawska et al., 1998b; Wåhlin et al., 2001),

Published by Copernicus Publications on behalf of the European Geosciences Union. 
variations in particle number consistent with daily patterns of traffic (Harrison et al., 1999) and wind direction (see also Morawska et al., 2002), and higher number concentrations when the wind blows from the road (Hitchins et al., 2000), in areas of higher traffic density (Hussein et al., 2005; Harrison et al., 1999) and during the week, when traffic levels are higher (Morawska et al., 2002).

Particle size is determined by the particle generation process and in turn it influences particle behaviour and other important chemical and physical properties. Therefore, the analysis of particle size distribution can be useful in the interpretation of the properties of the distribution. Different descriptors of the particle number size distribution (NSD) have been used to characterize the source signatures of different types of emissions, for instance petrol (Morawska et al., 1998b) and diesel exhaust (Morawska et al., 1998a; CONCAWE, 2001; Virtanen et al., 2004) and the NSD spectra from different environments (e.g. Morawska et al., 1999b; Flocas et al., 2006).

Urban ambient air quality investigations have found variations in the NSD spectra obtained from different locations in the same city (e.g. Hussein et al., 2004, 2005; Salma et al., 2002) but these studies have focussed on the differences in concentration levels rather than the underlying geometries of the distributions. Therefore the existing information on the spatial variation of the NSD in urban areas remains incomplete.

The present investigation aims to analyse the spatial variation of the NSD spectra in a large city in the southern hemisphere, using data collected at nine different locations, and test the hypothesis that the spectra is evenly distributed throughout the area. The objective was to compare the average spectra using different descriptive size distributions parameters, and to evaluate the relative contribution of UFPs and nanoparticles $(<50 \mathrm{~nm})$ to the local airborne particle number.

\section{Methodology of the investigation}

\subsection{The city of Brisbane}

Brisbane is the capital of the state of Queensland, Australia, and is located in the southeast coast of the state. It has a population of about 1.8 million people, making it the third largest city in the country and the first in terms of population growth. The city straddles the Brisbane River, and is located in a low-lying floodplain, although the area is dotted by large hills reaching up to $300 \mathrm{~m}$.

Brisbane's climate is the sub-tropical humid type (Bureau of Meteorology, 1983). The warm season takes place between November and April, and is characterized by high relative humidity, strong winds with average of $11-21 \mathrm{~km} \mathrm{~h}^{-1}$ and frequent rain. The cool half of the year (May-October) is dry (0-50\% relative humidity) with very low wind speeds thus increasing the persistence time of air pollutants.

The rapid population growth and consequently increasing number of vehicles on the road pose a serious challenge to the air quality of the city. In a recent five-year study in the central business district (CBD) of Brisbane (Mejia et al., 2007), we found that although particle number concentration levels compared favourably with other cities around the world, emissions from a nearby freeway resulted in increased total and ultrafine particle concentrations by $105.3 \%$ and $81.5 \%$ respectively whereas non-freeway emissions remained unchanged. These conclusions were based on the available data and their associations with the daily local pattern of wind direction.

Hazard-reduction burning, practiced during the cold season in the outer agricultural and forest areas, is another important contributor to the particle number in the region. On these occasions, the city may be covered in smoke carried through the drainage flows. Commercial and industrial sources include a major airport and a seaport, oil refineries, a power station, and a number of manufacturing industries in the outer suburbs.

\subsection{Description of the instrumentation}

A TSI model 3394 SMPS was used to measured NSD data in the range $15-700 \mathrm{~nm}$. Details of the operation and calibration of the instrument have been provided in previous publications (e.g. Hitchins et al., 2000; Morawska et al., 1998b) and briefly summarised here. The SMPS consists of a TSI 3071A Electrostatic Classifier (EC), which classifies the particles by their ability to transverse an electric field, and a TSI 3010 Condensation Particle Counter (CPC), which measures their concentration. The SMPS was calibrated before and after the measurement period for the PSD using standard $100 \mathrm{~nm}$ latex spheres. The entire system is automated and is equipped with customized software. This software collects and stores sample data, which can then be exported to other applications.

\subsection{Location of the monitoring sites and sampling proce- dure}

Particle number size distribution and temperature data were collected at nine different locations in Brisbane. Table 1 summarizes the details of these locations and their corresponding databases including the area classification, distance to the $\mathrm{CBD}$, number of recorded cases and the percentage of the retained observations. More details are provided below. Unless otherwise indicated, the measurements were conducted at ground level, at an approximate height of 1.5 and 5-15 m to the road, with the principal road consisting of two lanes travelling in each direction:

1. Queensland University of Technology Air Monitoring Research Station (QUT AMRS) - A joint venture between QUT and the Environmental Protection Agency. 
Table 1. Summary of the monitoring sites.

\begin{tabular}{|c|c|c|c|c|c|c|c|}
\hline Site & \# Type of Environment & $\begin{array}{c}\text { Travel Speed } \\
\left(\mathrm{km} \mathrm{h}^{-1}\right)\end{array}$ & Monitoring Period & $\begin{array}{c}{ }^{*} \text { Recorded } \\
\text { Observations }\end{array}$ & $\begin{array}{l}\text { Scan Time } \\
(\mathrm{s})\end{array}$ & $\begin{array}{c}\text { Data Retention } \\
(\%)\end{array}$ & $\begin{array}{c}\text { Approx. Distance } \\
\text { to } * * \mathrm{CBD}\end{array}$ \\
\hline QUT AMRS & Urban-Freeway & $70-90$ & 1 June 1995-7 Nov 2000 & 24026 & 90 & 83.3 & Within CBD \\
\hline Brisbane Square (BSQ) & Urban-Commercial & $50-60$ & 18-24 Jan 2004 & 6458 & 180 & 99.5 & Within CBD \\
\hline $\mathrm{PAH}$ & Commercial-Suburban & $60-70$ & 30 July-23 Oct 1999 & 8390 & 300 & 99.9 & $4 \mathrm{~km} \mathrm{~S}$ \\
\hline Tora St & Freeway & $100-120$ & 16 Sep 1998-3 June 1999 & 8626 & 300 & 89.2 & $10 \mathrm{~km} \mathrm{~S}$ \\
\hline Archerfield & Industrial-Commercial & $60-70$ & 17-24 June 2002 & 1802 & 300 & 100.0 & $11 \mathrm{~km} \mathrm{~S}$ \\
\hline ANZ & Commercial-Suburban & $60-70$ & 1-8 July 2002 & 1917 & 300 & 98.7 & $11 \mathrm{~km} \mathrm{~S}$ \\
\hline Garden City & Commercial & $60-70$ & 24 June-1 July 2002 & 1561 & 300 & 100.0 & $11 \mathrm{~km} \mathrm{~S}$ \\
\hline Mt Gravatt-Capalaba Rd (MGC Rd) & Suburban & $60-70$ & $6-17$ June 2002 & 1733 & 300 & 100.0 & $11 \mathrm{~km} \mathrm{~S}$ \\
\hline Port of Brisbane (BP) & Marine-Industrial & $60-70$ & 12 May-9 June 2006 & 5904 & 300 & 99.6 & $16 \mathrm{~km} \mathrm{NE}$ \\
\hline
\end{tabular}

\# With the exception of the freeway type, which is assumed to be continuous non-stop driving mode, traffic is assumed to travel in stop-start mode.

* Based on 5-min averages of submicrometre particles.

** Central Business District of Brisbane.

The station is located on the sixth floor of a building in QUT Gardens Point campus, at the southern end of the Brisbane CBD. The height of the station is about the same as that of the Southeast Freeway, located approximately $100 \mathrm{~m}$ south to the station. The freeway consists of three lanes travelling on each direction. For the purpose of brevity, the site be referred here as QUT.

2. Brisbane Square (BSQ) - Located in the heart of the Brisbane CBD, surrounded by four busy roads $15-20 \mathrm{~m}$ wides and buildings $15-30 \mathrm{~m}$ tall with one building reaching a height of $112 \mathrm{~m}$.

3. Princess Alexandra Hospital (PAH) - Monitoring was conducted on a pedestrian bypass, connecting two fivestory buildings, $3.5 \mathrm{~m}$ directly above a busy road and a traffic light.

4. Tora St - On Tora St Bridge, $3.5 \mathrm{~m}$ directly above the freeway, about $10 \mathrm{~km}$ south to the CBD. The freeway consists of three lanes travelling in each direction.

5. Archerfield - In the south-eastern corner of a fast food restaurant car park, and a busy road. A traffic light intersection is located $5 \mathrm{~m}$ east to the site

6. ANZ sports complex (ANZ) - in the south-eastern corner of the complex. The terrain around the site consists of uncovered loose soil. The sampling location was surrounded two busy roads, $<5 \mathrm{~m}$ away from the site, intersecting at a traffic light, and a large sports complex.

7. Garden City (GC) - near the northeast corner of a major shopping centre car park. The shopping centre was bounded by two busy roads to the east and north, intersecting at a traffic light.

8. Mt Gravatt-Capalaba Rd (MGC Rd) - At the intersection of two busy roads in a residential area.
9. Brisbane Port (BP) - at the end of a bridge connecting the mainland to Fisherman's Island, between the road and a railway line. The road consists of one lane travelling on each direction. The area is surrounded by the mouth of the Brisbane River to the West and Moreton Bay to the $\mathrm{N}$ and $\mathrm{E}$, both approximately $60 \mathrm{~m}$ from the site.

Monitoring was conducted continuously throughout the day, except at QUT. At this site, prior to 1998, the SMPS was used for regular "grab sampling" of NSD in triplicates everyday in the morning (9:30-10:00) and the afternoon and at regular intervals throughout the day during periods characterized by notable atmospheric conditions such as haziness or hazard reduction burning; from January 1998, the data was collected at hourly intervals on a continuous basis.

The interruptions to monitoring were generally few and short, lasting only a few hours, except at Tora St, which lasted several days, and QUT, which lasted a maximum of three months. These two sites covered the earliest and longest campaigns and therefore the interruptions were mainly caused by equipment maintenance and competing usage priorities.

\subsection{Preparation of the database for statistical analyses}

The lognormal distribution is the most common method of representing the size distribution of atmospheric particles (e.g. Seinfeld and Pandis, 1998) for presenting and analysing the data, and was therefore the selected method for this study. There were occasional variations in the measured size range, so in order to maintain consistency concentrations outside the size range $15-300 \mathrm{~nm}$ were removed and the total concentration (i.e. $N_{15-300}$ ) was then calculated. The selected size range was based on the results of an earlier Brisbane investigation which found that throughout the day the number concentration of particles $>300 \mathrm{~nm}$ was between one and two orders of magnitude lower than that of particles $<300 \mathrm{~nm}$ (Mejia et al., 2007) and therefore their contribution could be 

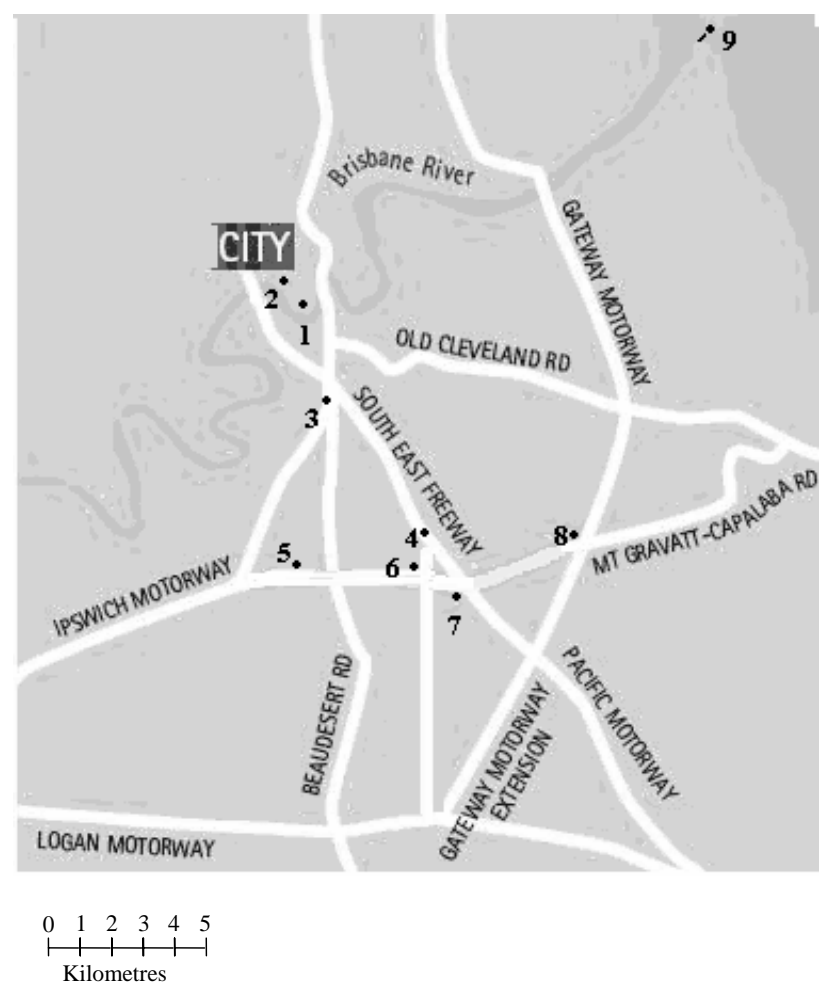

Fig. 1. Schematic representation (approximate scale: $5.4 \mathrm{~mm}=1 \mathrm{~km}$ ) of the sampling point locations: (1) QUT, (2) Brisbane Square, (3) Princess Alexandra Hospital, (4) Tora St, (5) Archerfield, (6) ANZ Sports Complex, (7) Garden City, (8) Mt Gravatt-Capalaba Rd, and (9) Brisbane Port.

considered negligible. The second step was to obtain the relative contribution of each channel to the particle number by dividing its concentration over the $N_{15-300}$. This was done with the objective of allowing comparisons of the underlying geometry of different NSD spectra, regardless of their actual concentration levels.

The data were divided into major subsets based on wind originating from the principal road (within $\pm 45^{\circ}$ of the direction perpendicular to the road), wind towards this road, and in some cases, wind from other major physical structures. These subsets were further divided into weekdays and weekends. The aim was to determine whether wind sector or day of the week had an effect on the spectra.

The datasets were subjected to outlier analysis in order to identify and remove extreme values that may lead to an incorrect interpretation of the data. There are several techniques available for outlier identification (e.g. Abu-el-zeet et al., 2002) and their selection depends on the characteristics of the dataset. In the present investigation, outliers were detected using the methodology described in Yu et al. (2004) and briefly summarized here. This is a two-stage graphical and statistical procedure used in the identification of discordant size distributions. The first stage uses the total concen- tration vs. the corresponding coefficient of variation, both in the logarithmic scale in order to detect size distributions isolated from the main cluster of observations. In the second stage, individual outliers are identified by the Generalized Extreme Studentized Deviate (ESD) Many-Outlier Procedure and the modified z-score (see also Barnett and Lewis, 1994, for more details).

After the outliers were identified and eliminated, the next move was to select those NSD properties to be analysed as well as appropriate data analysis procedure. The modal structure (the graphical representation of the shape of the number size distribution function) has the advantage of providing a detailed description of the structure of the distribution, provided that the diameter size range has been carefully selected in order to maximise the amount of detail of the fraction dominating the particle parameter of interest and that size intervals are of the same width in the same scale. The particle number is overwhelmingly dominated by particles $<300 \mathrm{~nm}$ (e.g. Eleftheriadis et al., 2006); therefore, the selected size range was therefore considered appropriate for this study.

The Kolmogorov-Smirnov (K-S) test was used to compare the modal distribution obtained from each site. The use and applicability of this test for comparing particle size distributions containing a large number of sizing channels has been described by Heitinbrink et al. (1990) and the details of the application of this technique for measured SMPS data have provided by Morawska et al. (1999a) and further expanded here. The K-S test compares the largest distance between two cumulative distribution functions against a critical value $\left(D_{\alpha}\right)$, which is calculated from the equation:

Where $c(\alpha)$ is the confidence level $(\alpha)$ coefficient, and $n_{1}$ and $n_{2}$ are the sizes of the two samples. For a $95 \%$ confidence level, the value of $c(\alpha)$ is 1.36 (Gibbons and Chakraborti, 2003). The K-S tests were performed using SPlus 6.1 (2002, Insightful Corp.).

Two other commonly employed parameters are the number median diameter (NMD), which is also calculated from the cumulative distribution function, and the geometric standard deviation (GSD), which measures the width of the distribution. Datasets were compared through one-way ANOVA tests. Homogeneity of variances was analysed using Levene's test. Pairs of means were then compared using least significant difference (LSD) tests in the case of equal variances and Games-Howell tests in the case of unequal variances.

\section{Results}

\subsection{Modal structure of the NSD}

Figure 2 shows the average modal structure of the submicrometre (referred in this paper, unless otherwise indicated to particles $<300 \mathrm{~nm}$ ) particle NSD obtained from each site. 

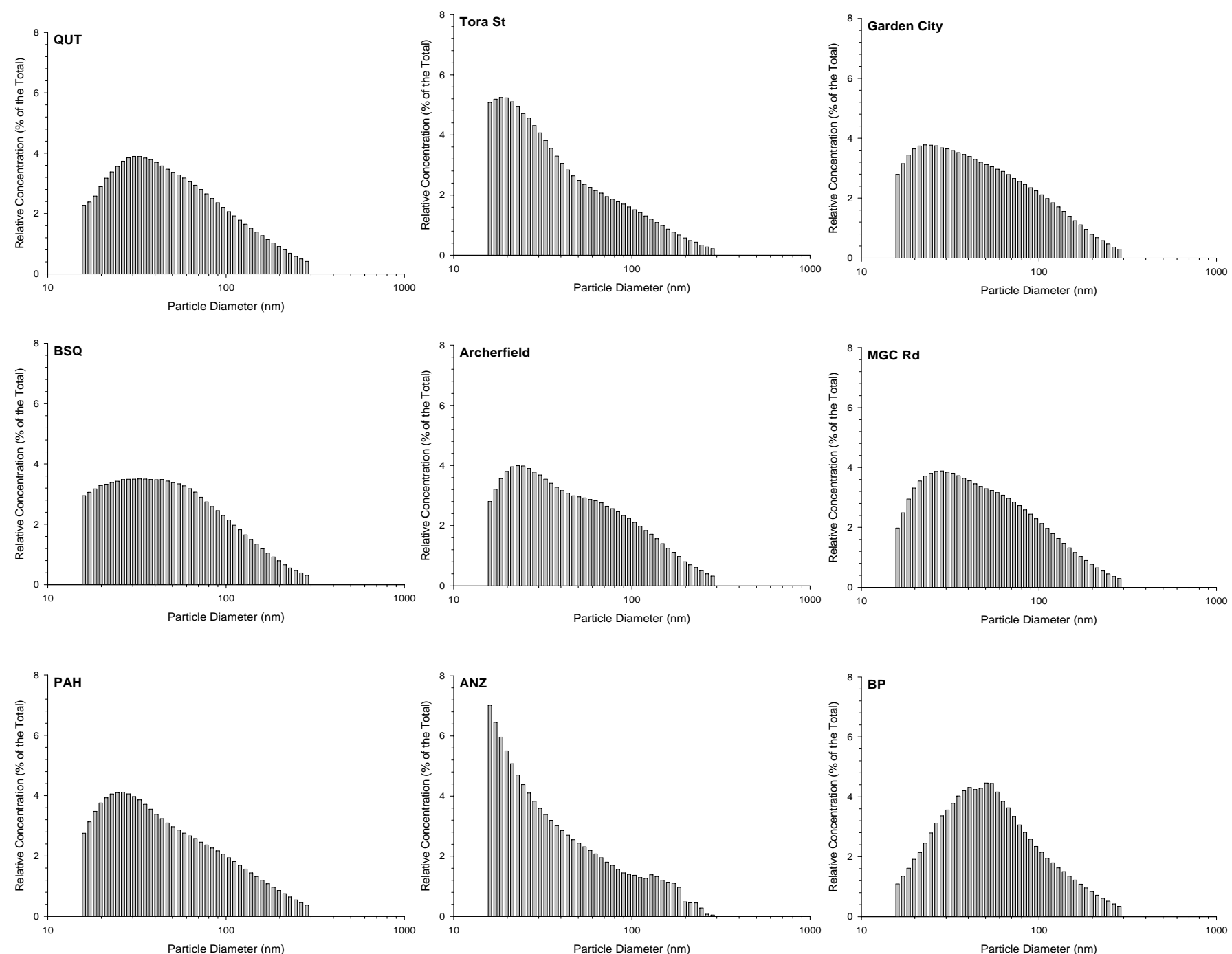

Fig. 2. Average particle NSD spectra in the range $15-300 \mathrm{~nm}$ of data collected at nine different locations in Brisbane, Australia.

For comparison purposes, the vertical axes have been drawn to the same scale. The figures indicate the percentage of the total concentration in the range $15-300 \mathrm{~nm}$. As shown by these results, the NSDs were likely to have at least two peaks, but partly masked: one occurring below $30 \mathrm{~nm}$, and a second peak or protrusion suggesting its presence, is observed at above $50 \mathrm{~nm}$. QUT was the exception by having a clearly unimodal distribution. At BP, the distribution appears to be bimodal although the second peak, at around $50 \mathrm{~nm}$, has a higher concentration than the first peak, which occurs at around $40 \mathrm{~nm}$. At ANZ site, no peak in the lower size range was observed, and the data suggests that it was located below the lower end of the size range measured in this study; also, the second mode is above $100 \mathrm{~nm}$ and its sources are yet to be determined.
The NSD data was then used to calculate the cumulative NSD and the resulting spectra are shown in Fig. 3. The objective was to assess the contribution of UFPs and nanoparticles $(<50 \mathrm{~nm})$ to the particle number and identify the location of the NMD. The results indicated that UFPs contributed to around $85 \%$ of the particle number and nanoparticles to around $60 \%$; at ANZ and Tora St sites the contribution of UFPs and nanoparticles were, respectively, $90 \%$ and $70 \%$, probably reflecting their close proximity to the road $(<5 \mathrm{~m})$. At BP, UFPs although the contribution of ultrafine particles is consistent with those from the other sites (around 83\%), the contribution of nanoparticles drops to $50 \%$, indicating the much higher contribution of diesel trucks. With regard to NMD, the plots show that most NMDs fall in the $40 \mathrm{~nm}$ region, except at Tora St and ANZ, where it falls around $30 \mathrm{~nm}$, and BP, where it shifts to nearly $50 \mathrm{~nm}$. 

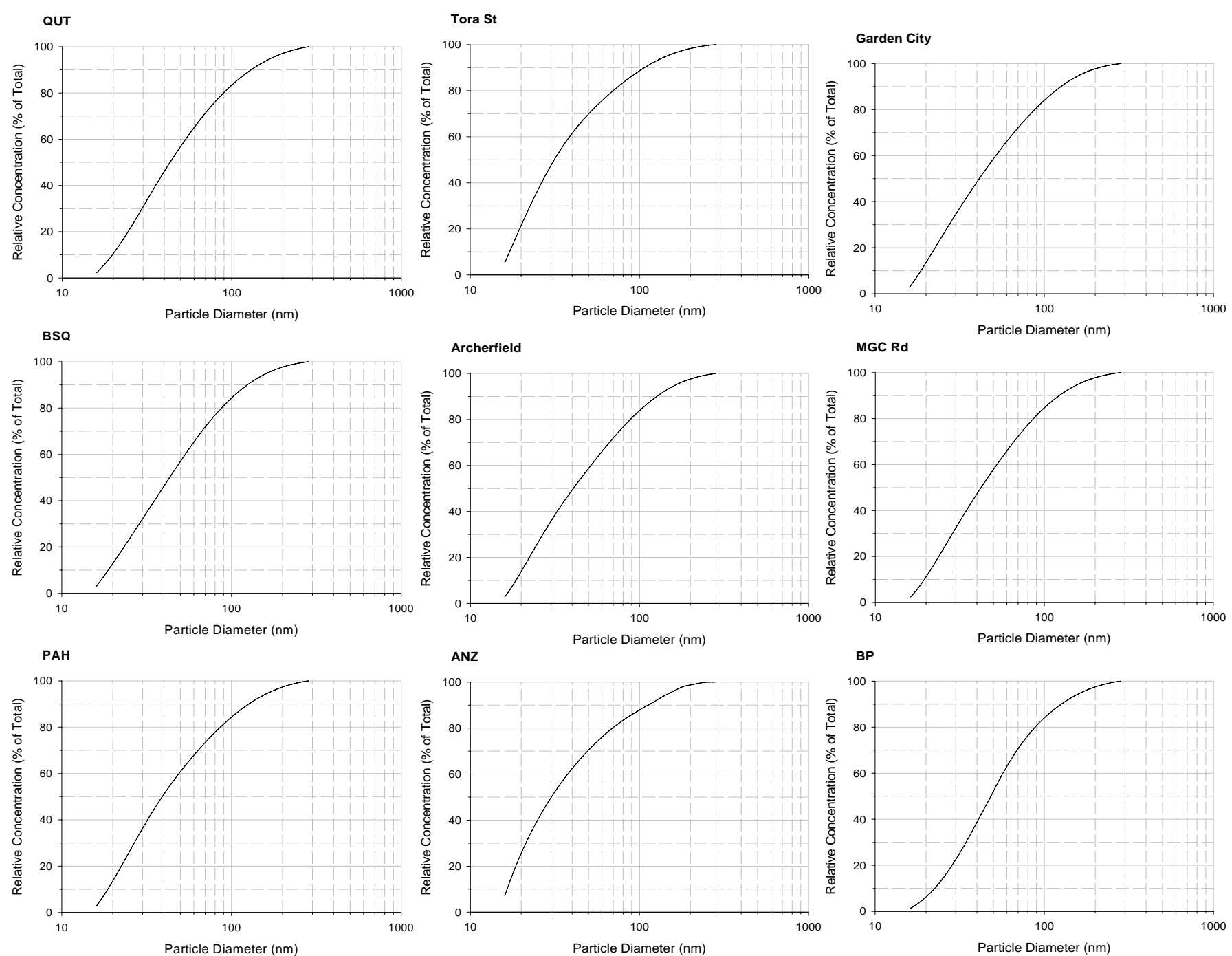

Fig. 3. Cumulative particle NSD in the range $15-300 \mathrm{~nm}$ obtained from the average modal structure obtained at the nine selected sites.

The K-S test compared the distributions between each pair of spectra and the results are shown in Table 3. The tests showed that the spectra differed significantly between all of the sites, thereby indicated that the composition of the emissions is not evenly distributed around the area. Despite these differences, there were three major groups of spectra: the first group corresponded to the sites with peaks at around $30 \mathrm{~nm}$ (PAH, Archerfield, Garden City, MGC Rd, QUT and BSQ); the second group was represented by the sites dominated by peaks $<25 \mathrm{~nm}$ (Tora St and ANZ); and the third group was represented by one site (BP) where particle number peaked at around $50 \mathrm{~nm}$. Although these results hint at differences in the vehicle mix, there was no traffic data available and therefore the effect of traffic composition on size distribution could not be analysed in more detail.
Comparisons between the data subsets for each site indicated that there were no significant differences between wind direction sectors or between weekdays and the weekend $(p>0.05)$. Therefore, the extracted spectra above can be considered representative of their corresponding sites. There were minor exceptions, the most significant being at BSQ between weekdays and the weekend $(p=0.02)$. The resultant spectra are shown in Fig. 4a and b respectively. During the week, the distribution is bimodal with peaks at around 30 and $60 \mathrm{~nm}$ while on the weekend it is unimodal peaking at around $35 \mathrm{~nm}$.

3.2 Number median diameter (NMD) and geometric standard deviation (GSD)

ANOVA tests applied to NMD found statistically significant differences between sites. Post hoc comparisons indicated 

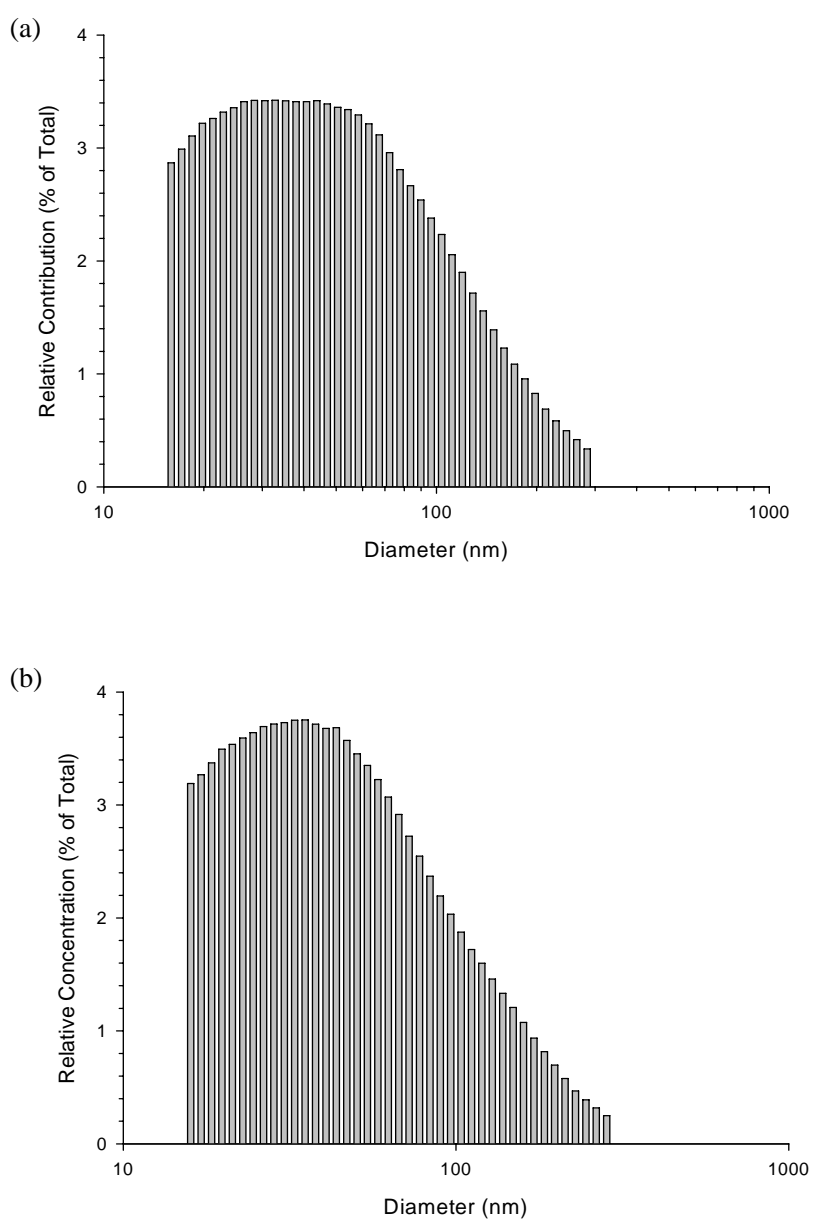

Fig. 4. Observed differences in NSD spectra obtained at BSQ during (a) weekdays and (b) the weekend.

that with the exception of PAH, Archerfield, Garden City and MGC Rd, the mean values differed significantly. This was largely expected due to the large sample sizes. However, the magnitudes of most of the differences were found to be very small (maximum of $5 \mathrm{~nm}$ ) and therefore not practically important, so in practice, they could be grouped as follows: Group 1 was represented by NMD in the $40-50 \mathrm{~nm}$ size region (the four sites above plus BSQ and QUT); Group 2 comprised those in the $30 \mathrm{~nm}$ region (ANZ and Tora St); and Group 3 belonged to the $60 \mathrm{~nm}$ region (BP). The mean values for each site are shown in Fig. 5, with the continuous lines used to separate the major groups.

The statistical tests indicated that mean GSD differed very little between sites (mean 1.94-2.02, s.d. 0.12-0.17) except at BP, where it was significantly greater (mean 2.46 , s.d. 0.85). In other words, the size distribution showed more or less the same level of polydispersity, except at BP.

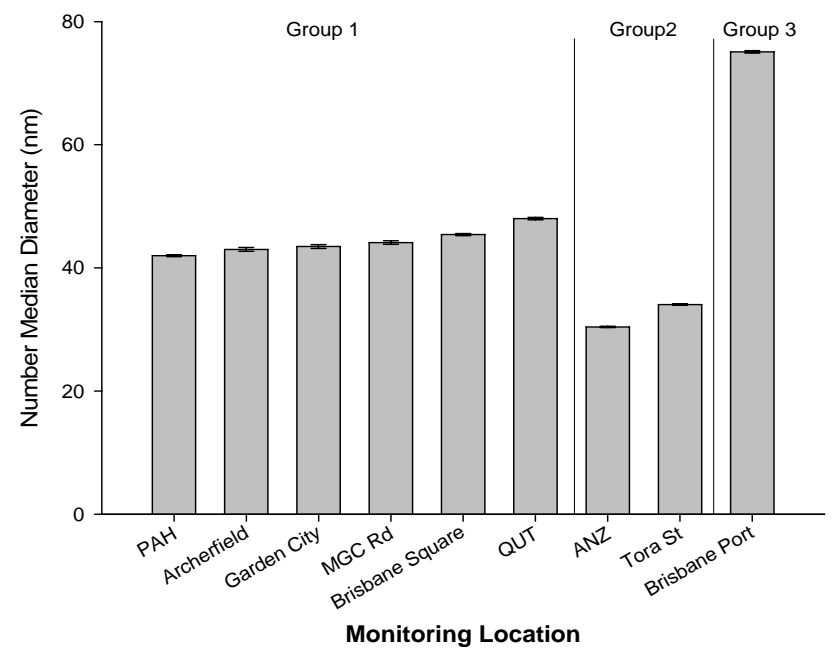

Fig. 5. Average NMD per site. The error bars represent the corresponding standard errors. The continuous lines are used to group the sites into three major categories.

\subsection{Effect of differences in time period}

The NSD measurements were conducted during different campaigns, each having different duration, as indicated in Table 1. The results proved that despite the differences in time period the ranges of obtained values for the location of the peaks and NMD fell respectively, around 30 and $40 \mathrm{~nm}$, with the exception of BP site where the corresponding values were around 50 and $60 \mathrm{~nm}$. Similarly the ranges for the contribution of ultrafine particles and nanoparticles to the total concentration were very narrow (around $10 \%$ between their corresponding minima and maxima). The only exception was BP site but this cannot be explained by seasonal differences, particularly of temperature, as the averages range between $14.0^{\circ} \mathrm{C}$ and $26.4^{\circ} \mathrm{C}$ (Table 2). As Table 2 shows, although there are obvious differences in particle concentration levels (ranging from 7.2 to $45.6^{\times} 10^{3} \mathrm{~cm}^{-3}$ ), the range of temperatures is very narrow, with average values ranging between $14.0^{\circ} \mathrm{C}$ and $26.5^{\circ} \mathrm{C}$. Therefore, it is very clear that the sampling periods had no effect on the distributions and particle concentration levels.

\section{Discussion}

The size distribution of submicrometre particle data, collected at nine different sites in urban atmosphere of Brisbane, in the range $15-300 \mathrm{~nm}$ using the lognormal scale, were analysed in terms of their modal structure and NMD, covering a total period of 11 years. Larger particles were excluded from the study as we found in a previous investigation that their concentrations were between one and two orders of magnitude lower than the above range (Mejia et al., 2007), and 
Table 2. Recorded temperatures and particle concentration levels at each site.

\begin{tabular}{lcccccc}
\hline \multirow{2}{*}{ Site } & \multicolumn{3}{c}{ Temperature $\left({ }^{\circ} \mathrm{C}\right)$} & \multicolumn{3}{c}{ Conc. $\left(\times 10^{3}\right.$ Particles $\left.\mathrm{cm}^{-3}\right)$} \\
& Min. & Max. & Ave. & Min. & Max. & Average \\
\hline QUT AMRS & 0.0 & 40.0 & 21.0 & 0.1 & 215.1 & 7.2 \\
Brisbane Square (BSQ) & 8.0 & 35.5 & 26.4 & 0.7 & 120.3 & 11.3 \\
PAH & 5.9 & 27.7 & 16.5 & 0.5 & 104.0 & 15.5 \\
Tora St & 9.3 & 35.2 & 21.9 & 0.1 & 314.0 & 25.5 \\
Archerfield & 0.4 & 24.9 & 14.9 & 0.5 & 83.0 & 17.5 \\
ANZ & 5.7 & 25.2 & 14.3 & 3.6 & 242.1 & 45.6 \\
Garden City & 6.7 & 23.7 & 14.0 & 1.7 & 111.5 & 15.0 \\
Mt Gravatt-Capalaba Rd (MGC Rd) & 6.9 & 30.7 & 16.6 & 0.8 & 45.7 & 5.7 \\
Port of Brisbane (BP) & 9.0 & 25.1 & 17.2 & 0.2 & 238.6 & 13.2 \\
\hline
\end{tabular}

therefore, we did not expect that they would significantly affect the size distribution.

\subsection{Modal structures}

As can be seen in Fig. 2, the modal structures and corresponding concentration levels were very similar to those reported from traffic and urban emissions (Morawska et al., 1999b). Particle number peaked at below $30 \mathrm{~nm}$ and a second peak was observed, or at least suggested by the results, in the range 50-100 nm, except at QUT, where the distribution was clearly unimodal. The results are consistent with the modal structures observed in petrol and diesel exhaust, whose respective NSDs are dominated by the ranges 20-60 and 20-120 nm (Maricq et al., 1999; Gouriou et al., 2004; Morawska et al., 1998a).

The first peak $(<30 \mathrm{~nm})$ predominates and is indicative of the predominance of petrol emissions in Brisbane, corroborating earlier findings (Holmes et al., 2005; Morawska et al., 1998b, 1999b), and also hint at the presence of diesel traffic (Morawska et al., 1998a). These particles belong to a size category known as nanoparticles $(<50 \mathrm{~nm})$, which are formed by primary carbonaceous emissions from petrol, and the supersaturation of semivolatile precursors due to the rapid cooling of both petrol and diesel traffic exhaust gas resulting in homogeneous nucleation (Bukowiecki et al., 2002; Imhof et al., 2005b; Kittelson et al., 2002). This has been shown to be a process that instantly (1-3s) yields a high number of nanoparticles (Kittelson et al., 2000).

The second peak, in the range $50-100 \mathrm{~nm}$, as already discussed, is indicative of diesel fuel. These particles consist predominantly of soot aggregates from incomplete combustion processes (Imhof et al., 2005a). Research from bench tests suggests that nanoparticles dominate the low engine load whereas the peak above $50 \mathrm{~nm}$ corresponds to high loads (Sturm et al., 2003). With the exception of QUT and Tora St, sampling took place close to traffic lights. During each scan, the lights changed, on average, ten times. As a result, engine loads varied regularly, being highest during acceleration.
The distributions at ANZ and Tora St are clearly dominated by the smaller particles, peaking at $<25 \mathrm{~nm}$. No peak was observed at ANZ site, and the data indicates that the peak is located below $15 \mathrm{~nm}$. Modal diameters below this limit have been observed in urban air (e.g. Shi et al., 2001). Particle NSD has been observed to change with distance to the road, shifting to a larger diameter the further away downwind (Pirjola et al., 2006; Zhu et al., 2002b). Research has found that the concentration of particles $<50 \mathrm{~nm}$ decrease more rapidly than that of particles $>100 \mathrm{~nm}$ and concluded that coagulation is more important than atmospheric dilution for UFPs whereas the reverse is true for larger particles (Zhu et al., 2002b). Other investigations, on the other hand, have found that dilution is as important as coagulation in changing the concentration of UFPs with increasing distance to the road (e.g. Zhu et al., 2002a). Tora St and ANZ were very close to the road $(<5 \mathrm{~m})$ and therefore it is reasonable to conclude that the distributions observed at these two sites reflect their close proximity to traffic.

Of the other sites, only PAH was as close to the road. At this site, however, smaller particles are less dominant than at Tora St and ANZ. There is a greater flow of diesel vehicles around PAH, which partially explains the results. There were similarities but also differences in sampling conditions between PAH and the two sites above. As in Tora St, sampling took place directly above the road. The main difference was the traffic flow pattern, travelling continuously at $100-110 \mathrm{~km} \mathrm{~h}^{-1}$ at Tora St whereas at PAH sampling took place directly above a traffic light. Gouriou et al. (2004) and Imhoff et al. (2005a) observed that, for diesel fuel, particles $>50 \mathrm{~nm}$ prevailed in stop-start traffic conditions. This can be explained by the higher engine loads associated with startacceleration conditions near these lights, resulting in high emission rates of soot particles. At ANZ, sampling took place near a traffic light but unlike PAH it was at ground level. Research on the horizontal and vertical distribution of particles around buildings (Morawska et al., 1999a), however, found no association between height and total particle 
Table 3. Kolmogorov-Smirnov test results on average spectra.

\begin{tabular}{lcccccccc}
\hline Site & ANZ & Archerfield & BP & BSQ & Garden City & MGC Rd & PAH & QUT \\
\hline Archerfield & 0.122 & & & & & & & \\
BP & 0.171 & 0.098 & & & & & & \\
BSQ & 0.146 & 0.049 & 0.073 & & & & & \\
Garden City & 0.122 & 0.024 & 0.098 & 0.024 & & & & \\
MGC Rd & 0.122 & 0.024 & 0.073 & 0.024 & 0.024 & & & \\
PAH & 0.098 & 0.024 & 0.098 & 0.049 & 0.024 & 0.049 & & \\
QUT & 0.143 & 0.049 & 0.073 & 0.024 & 0.049 & 0.024 & 0.049 & \\
Tora St & 0.049 & 0.122 & 0.171 & 0.122 & 0.122 & 0.122 & 0.098 & 0.122 \\
\hline
\end{tabular}

number concentration. The meteorological conditions were similar at the three sites, with average wind speeds ranging between 1.5 and $2.1 \mathrm{~m} / \mathrm{s}$. Therefore, although it is obvious that the observed distributions at these sites reflect their different environments, there are influences other than traffic or meteorological conditions yet to be identified.

A small peak above $100 \mathrm{~nm}$ is observed at ANZ site although its concentration is close to the lowest in the ultrafine range. During this campaign, there was an episode when the entire city was covered in smoke. Although this peak may explain the reduction in visibility, the episode was of very short duration, approximately one day. In addition, the spectrum looks quite different from that associated with bushfire activity (Morawska et al., 1999b). At this stage, the causes remain unclear.

BP site differs from the other sites in that the peak in the size distribution shifts to a larger diameter, around $50 \mathrm{~nm}$. Free-flowing traffic at this site is dominated by diesel trucks, with average velocities of $70 \mathrm{~km} \mathrm{~h}^{-1}$. The smaller peak at $40 \mathrm{~nm}$ is consistent with the peak observed in sea breeze (Morawska et al., 1999b) probably resulting from homogeneous nucleation in marine boundary layer (Hoppel et al., 1990). The site was located at approximately $14 \mathrm{~m}$ above sea level, at the northern end of a bridge connecting the mainland to the seaport and therefore it is reasonable to interpret this peak as being associated with sea breeze. However, based on the NSD on marine aerosols (e.g. Bates et al., 2000; Eleftheriadis et al., 2006; Morawska et al., 1999b) a small peak in the range 100-200 $\mathrm{nm}$ was expected. The absence of this peak at the site therefore reflects the much stronger contribution of diesel traffic.

\subsection{Cumulative distributions}

Figure 3 shows that UFPs contribute between 82 and $89 \%$ of the total particle number and nanoparticles between $60 \%$ and $70 \%$. This is consistent with the NSD observed in urban aerosols (Morawska et al., 1998a, b; Shi et al., 2001). At BP site, although the contribution of UFP is very consistent with the other sites, the contribution of nanoparticles drops to around $50 \%$, reflecting the dominance of the larger ultrafine particles.

The K-S tests in Table 3 confirmed that all spectra had significantly different distributions. This supported the visible differences shown in Fig. 2. Despite the differences, the sites can be group into three major categories: (1) those with maximum concentrations in the $30 \mathrm{~nm}$ region (QUT, BSQ, PAH, Archerfield, Garden City and MGC Rd), (2) those with peak concentrations $<25 \mathrm{~nm}$ (Tora St and ANZ), and (3), a site with peak concentrations at around $50 \mathrm{~nm}$ (BP). The modal structures in the first category is characteristic of urban traffic emissions, particularly from petrol (Morawska et al., 1999b); the second category is clearly dominated by particles at the lower end of the size range, and it can be explained by the close proximity between the sites and the road; the spectrum in the third category is consistent with diesel emissions (Morawska et al., 1998a). Figure 1 shows that the sites corresponding to the first category are very widespread around the study area, those corresponding to the second category are very close to each other, surrounded by those in the first category and the site in the last category is clearly isolated from rest. Therefore, the interpretation of the data is influenced by the level of proximity between the sites.

The statistical analyses indicated that with only a few exceptions, wind direction or day of the week did not significantly affect the NSD. Based on what has already been discussed, it is reasonable to conclude that the spectra are heterogeneously distributed probably due to local differences in the contribution of petrol vehicles. At BP, the contribution of nanoparticles becomes reduced and this can be attributed to the much larger percentage of diesel trucks at this site.

At the BSQ site, the distributions differed between weekdays and the weekend and this is reflected in the location of the corresponding peaks (Fig. 4). This site was located in the heart of the CBD. This difference is explained by the difference in fleet composition during these days. The CBD serves as a hub for public transport services, and $85 \%$ of buses operate on diesel fuel. Petrol traffic is more dominant during the weekend, resulting from a reduction in bus services, even though traffic flow rate is significantly reduced. 


\subsection{Number median diameters}

In addition to the modal structure, the size distributions were analysed in terms of their NMDs (Fig. 5). Unlike the modal structures, some sites were found to have similar NMD values. Based on the statistical results and the average values, the sites were grouped into three major groups, and these groups were consistent with those obtained for the modal structures.

Although some variations between sites were found within the groups, the magnitude of these differences was very small and not practically important. For instance, the NMDs consistently fall around or below the $40 \mathrm{~nm}$ region, which is a source signature of petrol traffic (Morawska et al., 1998b, 1999b). The only exception were BP site, where the average NMD is $59 \mathrm{~nm}$, reflecting the predominance of diesel trucks (Morawska et al., 1998a).

To deepen the analysis, the GSD were also compared and there was little variability among the sites, with average values falling around 1.96, although it was visibly higher at BP (2.46). In order to shed more light into the shape of the distributions, the correlation between NMD and GSD was analysed and although it was significant at the $99 \%$ confidence level $(p<0.01)$, it was rather weak $(r=-0.14)$. Therefore, the effect of NMD on the width of the distribution may not be important in practice.

\subsection{Effect of seasonality}

The interpretation of the results suggests that, with the exception of BP site, the distributions were unaffected by the differences in sampling period. A time series investigation (Mejia et al., 2007) found that, unlike in temperate latitudes, particle size distribution in Brisbane is unaffected by season of the year. This conclusion was based on seasonal analysis results on particle number and NMD, which showed no annual periodic behaviour. The lack of seasonality in Brisbane can be explained by the very small variations in meteorological conditions, for example air temperature, which in this study had a range of $10^{\circ} \mathrm{C}$ between the minimum and maximum averages (Table 2). There were obvious differences in particle number (Table 2), but these can be interpreted as resulting from varying distance to the road, traffic levels and composition rather than caused by seasonal differences.

\subsection{Summary and conclusions}

To summarise the findings from this study, the data were collected during different campaigns of varying durations spanning an 11-year period. The results indicated that there were statistically significant differences in the modal structures and therefore they showed that particle number size was heterogeneously distributed in Brisbane. UFPs and nanoparticles contributed, respectively, to around $82-89 \%$ and $60-$ $70 \%$ of the particle number. Although the contribution of
UFPs at the BP site, was similar to the other sites, the contribution of nanoparticles decreased to $50 \%$, reflecting its different environment. Particle number peaked at around or below $30 \mathrm{~nm}$ and NMD in the $40 \mathrm{~nm}$ region. Although some differences were also found for the NMD, there were four sites that had similar NMD values. Where statistically significant differences were found, in most cases, their magnitudes were very small and therefore not important in practice. Although the locations of the peaks varied between sites, in most cases half of the particle number was within approximately the same size range. Based on these results, the sites were divided into three major groups: (1) urban sites dominated by petrol traffic emissions, (2) sites dominated by the smaller particles probably caused by the proximity between the measurement points and the road, and (3) a site clearly dominated by diesel traffic. The average NSDs were clearly unaffected by differences in sampling periods. The locations of the peaks and NMD values consistently indicate that petrol vehicles are the dominant source, and therefore the results from the statistical tests hint at differences in traffic composition, as expected. At this stage, however, no association between traffic composition and size distribution could be established due to the limited traffic information available for this study. Future investigations should benefit by including traffic composition data.

Acknowledgements. The authors wish to express their appreciation to R. Jayaratne, G. Johnson and N. Holmes, from the International Laboratory of Air Quality and Health (ILAQH) and M. Jamriska (formerly from ILAQH and currently from the Australian Defence Academy), for supplying their data for the purposes of this project. Funding from the Australian Research Council is also gratefully acknowledged.

Edited by: V.-M. Kerminen

\section{References}

Abu-el-zeet, Z. H., Becerra, V. M., and Roberts, P. D.: Combined bias and outlier identification in dynamic data reconciliation, Comput. Chem. Eng., 26, 921-935, 2002.

Barnett, V. and Lewis, T.: Outliers in statistical data, Chichester, Wiley, 1994.

Bates, T. S., Quinn, P. K., Covert, D. S., Coffman, D. J., Johnson, J. E., and Wiedensohler, A.: Aerosol physical properties and processes in the lower marine boundary layer: a comparison of shipboard sub micron data from ACE 1 and ACE 2, Tellus B, 52, 258-272, 2000.

Bukowiecki, N., Dommen, J., Prevot, A. S. H., Richter, R., Weingartner, E., and Baltensperger, U.: A mobile pollutant measurement laboratory-measuring gas phase and aerosol ambient concentrations with high spatial and temporal resolution, Atmos. Environ., 36, 5569-5579, 2002.

Bureau of Meteorology: The Climate of Brisbane, Canberra, 1983.

Buzorius, G., Hameri, K., Pekkanen, J., and Kulmala, M.: Spatial variation of aerosol number concentration in Helsinki city, Atmos. Environ., 33, 553-565, 1999. 
CONCAWE: Measurement of the Number and Mass Weighted Size Distributions of Exhaust Particles Emitted from European Heavy Duty Engines (Report No. 01/51), Brussels, CONCAWE, Report No. 01/51, 2001.

Eleftheriadis, K., Colbeck, I., Housiadas, C., Lazaridis, M., Mihalopoulos, N., Mitsakou, C., Smolik, J., and Zdimal, V.: Size distribution, composition and origin of the submicron aerosol in the marine boundary layer during the eastern Mediterranean "SUB-AERO" experiment, Atmos. Environ., 40, 6245-6260, 2006.

Flocas, H. A., Assimakopoulos, V. D., and Helmis, C. G.: An experimental study of aerosol distribution over a Mediterranean urban area, Sci. Total Environ., 367, 872-887, 2006.

Gibbons, J. D. and Chakraborti, S.: Nonparametric Statistical Inference, New York, Marcel Dekker Inc., p. 583, 2003.

Gouriou, F., Morin, J.-P., and Weill, M.-E.: On-road measurements of particle number concentrations and size distributions in urban and tunnel environments, Atmos. Environ., 38, 2831-2840, 2004.

Harrison, R. M., Jones, M., and Collins, G.: Measurements of the physical properties of particles in the urban atmosphere, Atmos. Environ., 33, 309-321, 1999.

Heitinbrink, W. A., Baron, P., and Willeke, K.: Coincidence in time-of-flight aerosol spectrometres: phantom particle creation. Aerosol Sci. Tech., 14, 112-126, 1990.

Hitchins, J., Morawska, L., Wolff, R., and Gilbert, D.: Concentrations of submicrometre particles from vehicle emissions near a major road, Atmos. Environ., 34, 51-59, 2000.

Holmes, N. S., Morawska, L., Mengersen, K., and Jayaratne, E. R.: Spatial distribution of submicrometre particles and $\mathrm{CO}$ in an urban microscale environment, Atmos. Environ., 39, 3977-3988, 2005

Hong, Y. C., Lee, J. T., Kim, H., Ha, E. H., Schwartz, J., and Christiani, D. C.: Effects of air pollutants on acute stroke mortality, Environ. Health Persp., 110, 187-191, 2002.

Hoppel, W. A., Larson, R., and Vietti, M. A.: Aerosol size distributions and optical boundaries found in the marine boundary layer over the Atlantic Ocean, J. Geophys. Res., 95, 3659-3686, 1990.

Hussein, T., Hameri, K., Aalto, P. P., Paatero, P., and Kulmala, M.: Modal structure and spatial-temporal variations of urban and suburban aerosols in Helsinki-Finland, Atmos. Environ., 39, 1655-1668, 2005.

Hussein, T., Puustinen, A., Aalto, P., Makela, T., Hameri, K., and Kulmala, M.: Urban aerosol number size distributions, Atmos. Chem. Phys., 4, 391-411, 2004, http://www.atmos-chem-phys.net/4/391/2004/.

Imhof, D., Weingartner, E., Ordonez, C., Gehrig, R., Hill, M., Buchmann, B., and Baltensperger, U.: Real-World Emission Factors of Fine and Ultrafine Aerosol Particles for Different Traffic Situations in Switzerland, Environ. Sci. Technol., 39, 8341-8350, 2005a.

Imhof, D., Weingartner, E., Vogt, U., Dreiseidler, A., Rosenbohm, E., Scheer, V., Vogt, R., Nielsen, O. J., Kurtenbach, R., and Corsmeier, U.: Vertical distribution of aerosol particles and NOx close to a motorway, Atmos. Environ., 39, 5710-5721, 2005 b.

Jaenicke, R.:, Tropospheric aerosols, in: Aerosol-Cloud-Climate Interactions, edited by: Hobbs, P. V., London, Academic Press, 1993.

Kittelson, D., Watts, W., and Johnson, J.: Diesel Aerosol Sampling
Methodology - CRC E-43, Final report, Coordinating Research Council, 2002.

Kittelson, D. B., Johnson, J., Watts, W., Wei, Q., Drayton, M., Paulsen, D., and Bukowiecki, N.: Diesel sampling in the atmosphere, 2000.

Maricq, M. M., Podsiadlik, D. H., and Chase, R. E.: Examination of the Size-Resolved and Transient Nature of Motor Vehicle Particle Emissions, Environ. Sci. Technol., 33, 1618-1626, 1999.

Mejia, J. F., Wraith, D., Mengersen, K., and Morawska, L.: Trends in size classified particle number concentration in subtropical Brisbane, Australia, based on a 5 year study, Atmos. Environ., 41, 1064-1079, 2007.

Morawska, L., Bofinger, N., Kocis, L., and Nwankwoala, A.: Submicrometer and supermicrometer particles from diesel vehicle emissions. Environ. Sci. Technol., 32, 2033-2042, 1998a.

Morawska, L., Jayaratne, E. R., Mengersen, K., Jamriska, M., and Thomas, S.: Differences in airborne particle and gaseous concentrations in urban air between weekdays and weekends. Atmos. Environ., 36, 4375-4383, 2002.

Morawska, L., Thomas, S., Bofinger, N., Wainwright, D., and Neale, D.: Comprehensive characterization of aerosols in a subtropical urban atmosphere: particle size distribution and correlation with gaseous pollutants, Atmos. Environ., 32, 2467-2478, 1998 b.

Morawska, L., Thomas, S., Gilbert, D., Greenaway, C., and Rijnders, E.: A study of the horizontal and vertical profile of submicrometer particles in relation to a busy road, Atmos. Environ., 33, 1261-1274, 1999a.

Morawska, L., Thomas, S., Jamriska, M., and Johnson, G.: The modality of particle size distributions of environmental aerosols, Atmos. Environ., 33, 4401-4411, 1999b.

Pirjola, L., Paasonen, P., Pfeiffer, D., Hussein, T., Hämeri, K., Koskentalo, T., Virtanen, A., Rönkkö, T., Kesniken, J., Pakkanen, T. A., and Hillamo, R.: Dispersion of particles and trace gases nearby a city highway: mobile laboratory measurements in Finland, Atmos. Environ., 40, 867-879, 2006.

Salma, I., Dal Maso, M., Kulmala, M., and Zaray, G.: Modal characteristics of particulate matter in urban atmospheric aerosols, Microchem. J., 73, 19-26, 2002.

Seaton, A., Godden, D., MacNee, W., and Donaldson, K.: Particulate air pollution and acute health effects, The Lancet, 345, 176$178,1995$.

Seinfeld, J. H. Pandis, S. N.: Atmospheric Chemistry and Physics, New York, John Wiley \& Sons, Inc., p. 545, 1998.

Shi, J. P., Evans, D. E., Khan, A. A., and Harrison, R. M.: Sources and concentration of nanoparticles $(<10 \mathrm{~nm}$ diameter $)$ in the urban atmosphere, Atmos. Environ., 35, 1193-1202, 2001.

Sturm, P. J., Hausberger, S., Engler, D., Bacher, M., Lechner, B., and Rodler, J.: PM size distribution measurements in engine exhaust in context to road tunnel and ambient air measurements, Fifth international technion symposium, Vienna, Austria, http://www.technion.org/Pages/pdf/A_P3.pdf, 2003.

Virtanen, A. K. K., Ristimaki, J. M., Vaaraslahti, K. M., and Keskinen, J.: Effect of Engine Load on Diesel Soot Particles, Environ. Sci. Technol., 38, 2551-2556, 2004.

Wåhlin, P., Palmgren, F., and Van Dingenen, R.: Experimental studies of ultrafine particles in streets and the relationship to traffic, Atmos. Environ., 35, 63-69, 2001.

Yu, T. C., Teh, H. W., Jacques, P. A., Sioutas, C., and Froines, J. 
R.: Quality control of semi-continuous mobility size-fractionated particle number concentration data, Atmos. Environ., 38, 33413348, 2004.

Zhu, Y., Hinds, W. C., Kim, S., Shen, S., and Sioutas, C.: Study of ultrafine particles near a major highway with heavy-duty diesel traffic, Atmos. Environ., 36, 4323-4335, 2002a.
Zhu, Y., Hinds, W. C., Kim, S., and Sioutas, C.: Concentration and size distribution of ultrafine particles near a major highway, J. Air Waste Ma. Assoc., 52, 1032-1042, 2002b. 